\title{
A Novel Androgen Receptor Gene Mutation in A 46, XY Female with CAIS and Testicular Hamartoma
}

\author{
Marta Moretti ${ }^{1}$, Giulia Lanzolla ${ }^{2}$, Nicoletta Preziosi ${ }^{3}$, Paola Grammatico ${ }^{3}$, Enrico De Smaele ${ }^{1}$ Letizia Camerota $^{4}$, \\ Francesco Brancati ${ }^{4,5}$ and Costanzo Moretti ${ }^{6 *}$ \\ ${ }^{1}$ Department of Experimental Medicine, Sapienza University of Rome, Italy
}

${ }^{2}$ Department of Clinical and Experimental Medicine, University of Pisa, Italy

${ }^{3}$ Medical Genetics Laboratory, San Camillo-Forlanini Hospital, Italy

${ }^{4}$ Health and Environmental Sciences, University of L'Aquila, Italy

${ }^{5}$ Laboratory of Molecular and Cell Biology, Istituto Dermopatico dell'Immacolata IRCCS, Italy

${ }^{6}$ Department of Systems' Medicine, Tor Vergata University of Rome, Italy

Submission: May 06, 2019; Published: May 21, 2019

*Corresponding author: Costanzo Moretti, Professor of Endocrinology, Department of Systems' Medicine, Tor Vergata University of Rome, Via Montpellier 1, 00133 Rome, Italy

\begin{abstract}
Androgen insensitivity syndrome is an X-linked disorder caused by mutations in the $A R$ gene. Affected subjects have retained testis often removed after puberty to avoid potential malignant transformation. Here we report a 46 , XY individual with female phenotype, absent uterus and ovaries, intra-abdominal testis and testosterone plasma levels in the normal male range. A benign hamartoma developed in a testis retained in her abdomen for 47 years. Sequencing analysis of the coding regions of the AR gene (NM_000044) disclosed a novel c.932dupC variant in exon 1 , absent in population database and leading to frameshift and formation of a premature stop codon in AR (p. Lys313Glnfs*28). The truncated androgen receptor protein was not detectable by both $\mathrm{N}$-term and C-term antibodies in affected tissue. In the light of previous evidences showing an active crosstalk between steroid hormone receptors (including AR) and inflammatory signaling mediated by several cytokines and growth factors, we discussed that absent androgen receptor protein might modify gonadal tissue inflammatory milieu in retained gonads of CAIS patients and "protect" against testis cancer development.
\end{abstract}

Keywords: Androgen receptor; Complete androgen insensitivity syndrome; NF-kappaB; phospho-RelA; Testis; Hamartoma

Abbreviations: AIS: Androgen Insensitivity Syndrome; CAIS: Complete Androgen Insensitivity Syndrome; AR: Androgen Receptor; PAIS: Partial Androgen Insensitivity Syndrome; TGCT: Testicular Germ Cell Tumors; FSH: Follicular Stimulating Hormone; LH: Luteinizing Hormone; CA 125: Cancer Antigen 125; EMA: Epithelial Membrane Antigen; ER: Estrogen Receptor; PLAP: Placental Alkaline Phosphatase; PCR: Polymerase Chain Reaction; NFKB: Nuclear Factor Kappa B; DBD: DNA Binding Domain

\section{Introduction}

Androgen insensitivity syndrome (AIS) is a X-linked disorder caused by mutations in the $A R$ gene [1]. To date, more than 1000 AR gene variants have been reported [2]. In AIS, the presence of undescended testis leads to increased risk of germ cell malignancy after puberty, making prophylactic post pubertal gonadectomy generally advised to avoid potential malignant transformation [3]. Cryptorchidism is the most widely accepted risk factor for testicular cancer, associated with a relative risk of 3.7 to 7.5 times as compared to the general population. Furthermore, $5 \%$ of all testicular cancers associate with cryptorchidism [4]. Patients with complete AIS (CAIS) have female external genitalia, absent pubic and axillary hair, female breast development, blind shortened vagina, lack of Mullerian derivatives and abdominal or inguinal bilateral testes, with normal male karyotype [5]. The risk to develop a testicular germ-cell tumor (TGCT) is about 15$35 \%$ higher in retained normal testis and in partial androgen insensitivity syndrome (PAIS) with intra-abdominal gonads [6]. Conversely, the risk of TGCT in CAIS is lower, between 0.8 and $2 \%$, although few data are available, and the protective mechanisms have not yet been elucidated. Here we describe the clinical and molecular analyses of a patient with CAIS and a testicular hamartoma in a testis retained in the abdomen for 47 years.

A 47-year-old 46, XY female with a clinical diagnosis of CAIS, was referred to our clinic for right inguinal mass. The patient showed normal breast development and absent axillary and pubic hair. No inguinal, labial or adnexal masses were detected. Vulva 
and perineum were normal, and clitoris was not enlarged. She had a blind-ending vaginal pouch of $6 \mathrm{~cm}$ depth approximately and the cervix was invisible. Ultrasound and magnetic resonance imaging showed a $4 \times 3 \times 2.5 \mathrm{~cm}$ solid mass next to a multilocular cystic lesion $(2 \times 2.9 \mathrm{~cm})$ in the right pelvic sidewall without lymphadenopathy. Serum levels of FSH and LH were 4.7 (4-21 $\mathrm{IU} / \mathrm{mL})$ and 33 (5-25 IU/mL) respectively, serum testosterone was $9.78 \mathrm{nmol} / \mathrm{L}$ in the normal young male range $(8-35 \mathrm{nmol} / \mathrm{L})$, and $17 \beta$-estradiol was $29.5(27-123 \mathrm{pg} / \mathrm{mL})$. The tumor markers, including carcinoembryonic antigen, CA125, alpha-fetoprotein, lactate dehydrogenase and alkaline phosphatase, were negative. Laparoscopic exploration revealed the presence of undescended gonads. The left and right testis were hypoplasic and the right one showed also a solid mass at the upper pole.

Both gonads have been surgically removed. Their histological examination revealed sclerotic seminiferous tubules with Sertoli cells and maturation arrested germ cells. No signs of malignant transformation were detected. The mass from the right testis was nodular, encapsulated and yellowish. Its microscopic examination revealed seminiferous tubules devoid of lumen and containing Sertoli cells only. Interstitial stroma was scant and focally contained clusters of Leydig cells gathered in nodules. Mitotic activity was not prominent (Ki67-mib1 <1\%) and necrosis was not seen. Immunohistochemistry was positive for inhibin and negative for pancytokeratin, epithelial membrane antigen (EMA), estrogen receptor (ER) and placental alkaline phosphatase (PLAP). These findings were consistent with testicular hamartoma diagnosis. This neoplasia was part of a gonad retained in the abdomen for 47 years. Sequencing analysis of the coding regions of the AR gene (NM_000044) disclosed the c.932dupC nucleotide substitution. This variant was absent in population databases and leaded to frameshift and formation of a premature stop codon in AR (p. Lys313Glnfs*28) (Figure 1). The parents were not available to verify the origin of the identified variant. Immunohistochemistry with two different antibodies failed to detect the AR protein, in contrast to the normal relative levels of mRNA (Figure 2, panels A and B).

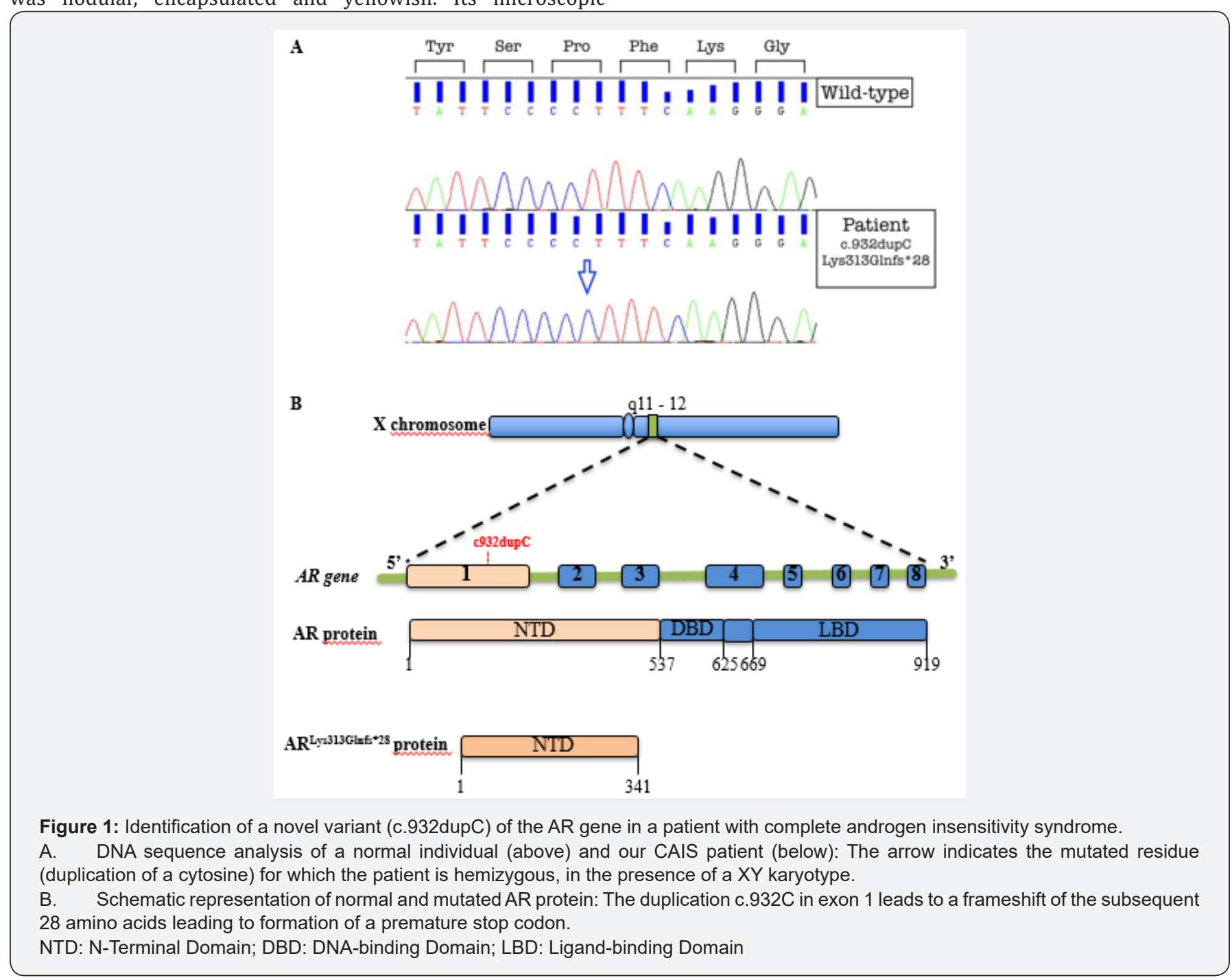




\section{Journal of Endocrinology and Thyroid Research}

A
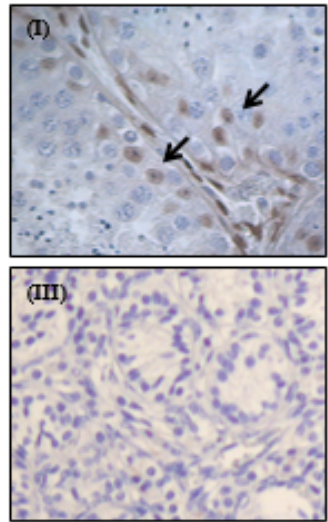

$\mathrm{C}$

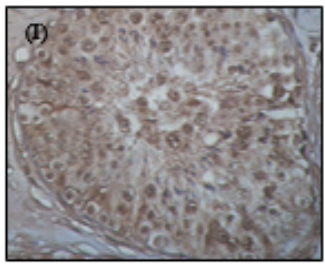

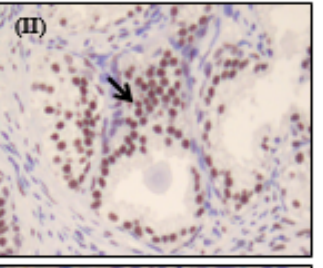
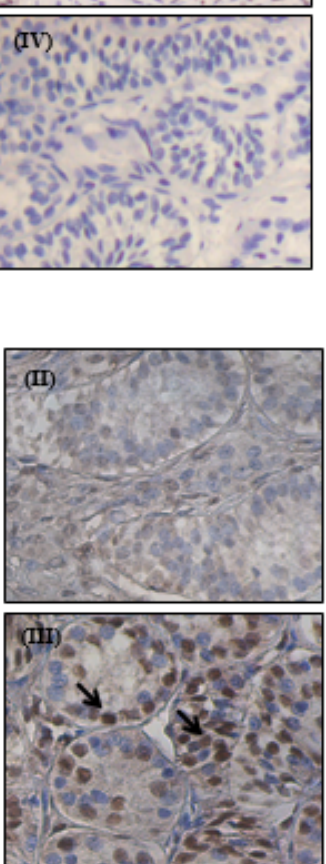
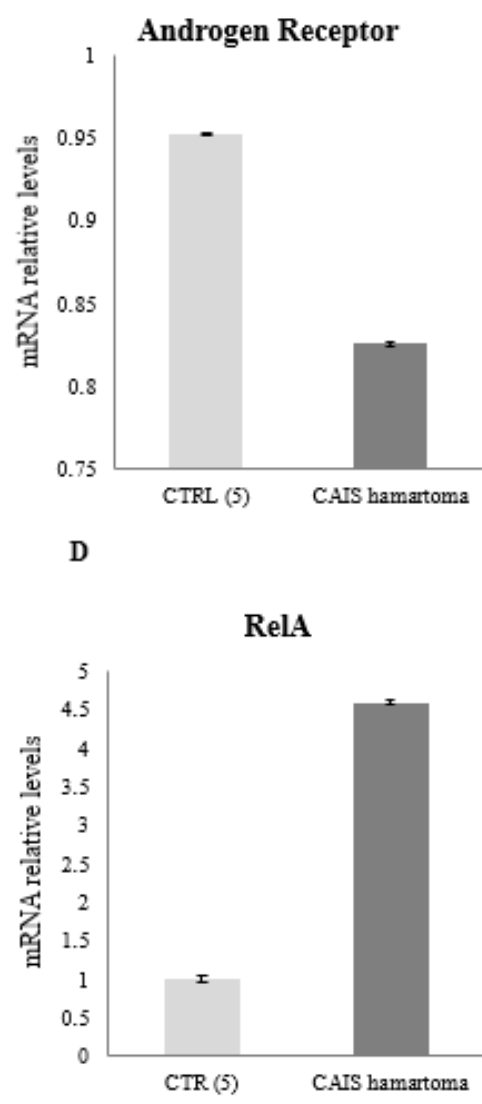

Figure 2: Androgen Receptor and NF-KB expression in the testis of our CAIS patient.

A. Representative immunohistochemical staining for AR. (I) In the normal testis, used as control, arrows indicate specific staining in Sertoli cells. A positive staining was also visible in the nucleus of peritubular myoid cells. (II) In the normal prostate tissue, used as a positive control, arrow indicate the AR staining in a group of epithelial columnar cells. (III) Any specific staining was detected in the CAIS testis and (IV) in the hamartoma tissue, indicating that AR protein expression is completely absent in these tissues.

B. RT q-PCR showing that the new nonsense mutation c.932dupC (p. Lys313GInfs ${ }^{\star 2} 28$ ) led to the synthesis of a normal quantity of AR mRNA transcript.

C. Representative immunohistochemical staining for phospho-RelA. (I) In normal testis, used as control, there was a high nuclear staining; (II) Any staining for phospho-RelA was detected in the testis of our CAIS patient; (III) In the hamartoma tissue, arrows indicate the cells expressing high level of phospho-RelA staining.

D. RT q-PCR showing the high expression of RelA mRNA in CAIS hamartoma as compared to normal testis used as control.

\section{Conclusion}

Here, we report a novel c.932dupC variant in exon 1 of the AR gene (p. Lys313Glnfs*28) in a 46, XY female patient with CAIS and testicular hamartoma diagnosed in a gonad retained in the abdomen for 47 years.

Patients affected with CAIS have a lower risk of developing malignant tumors than cryptorchid and PAIS patients [6], even if gonadal malignancy's incidence increases with age and prophylactic gonadectomy is recommended after puberty [3]. A low androgen environment may explain the high prevalence of germ cell anomalies in CAIS, not followed by the development of invasive tumors later in life [7]. However, the intimate molecular mechanisms protecting CAIS patients from the development of testicular tumors in retained gonads are not clear. Inflammatory signals enhancing cell proliferation might promote cancer development, while altered crosstalk between steroid hormone receptors and inflammatory signaling, mediated by several transcription factors, has been reported $[8,9]$. In detail, mutual regulation between $\mathrm{AR}$ and $\mathrm{NF}-\mathrm{\kappa B}$, a critical modulator of immune and inflammatory response, cell differentiation and survival, and tumor growth was identified $[10,11]$. NF- $\mathrm{KB}$ acts as a dimer composed of several combinations of the NF- $\kappa B$ family members among which RelA/p50 is the most common and active dimer expressed in human tissues, including testis [11].

These complexes are activated by different mechanisms leading to their phosphorylation and bind DNA target sequences ( $\kappa b$-sites) regulating gene expression. AR signaling pathway may result in increased or reduced NF- $\kappa B$ transcriptional activity, depending on ligand concentration [8,9]. Our CAIS patient showed 
testicular hamartoma without signs of neoplastic growth despite the long-lasting intra-abdominal testis retainment. In her tissue, AR was undetectable even though normal levels of AR-mRNA were measured (Figure 2, panels A and B). We hypothesize that the absence of AR was critical for NF- $\mathrm{KB}$ activation and expression, probably preventing the phosphorylation of its active form, the phospho-RelA. Interestingly, while NF- $\mathrm{KB}$ activity was absent in her testis (as shown by the presence of phospho-RelA protein), the hamartomatous tissue showed phospho-RelA positive cells suggesting the possibility of an alternative mechanism of NF$\kappa \mathrm{B}$ activation (Figure 2, panel C and D). Our work supports the hypothesis that the lack of functionally active gonadal AR might modify the local tissue inflammatory milieu, possibly protecting against cancer development through the activation of alternative, yet unknown, molecular mechanisms.

\section{References}

1. Tadakoro Cuccaro R, Hughes IA (2014) Androgen insensitivity syndrome. Curr Opin Endocrinol Diabetes Obes 21: 499-503.

2. Gottlieb B, Beitel LK, Nadarajah A, Paliouras M, Trifiro M (2012) The androgen receptor gene mutations database: 2012 update. Hum Mutat 33(5): 887-894.

3. Deans R, Crighton SM, Liao LM, Conway GS (2012) Timing of gonadectomy in adult women with complete androgen insensitivity syndrome (CAIS): patient preferences and clinical evidence. Clin Endocrinol (Oxf) 76(6): 894-898.

4. Ferguson L, How JJ, Agoulnik AI (2013) The fate of spermatogonial stem cells in the cryptorchid testes of RXFP2 deficient mice. PLoS One 8(10): e77351.

5. Hughes IA, Davies JD, Bunch TI, Pasterski V, Mastroyannopoulou K, et al. (2012) Androgen insensitivity syndrome. Lancet 380: 1419-1428.

6. Cools M, Drop SL, Wolffenbuttel KP, Oosterhuis JW, Looijenga LH (2006) Germ cell tumors in the intersex gonad: old paths, new directions, moving frontiers. Endocr Rev 27(5): 468-84.

7. Kaprova-Pleskacova J, Stoop H, Brüggenwirth H, Cools M, Wolffenbuttel $\mathrm{KP}$, et al. (2014) Complete androgen insensitivity syndrome: factors influencing gonadal histology including germ cell pathology. Mod Pathol 27(5): 721-30.

8. Jain G, Cronauer MV, Schrader M, Möller P, Marienfeld RB (2012) NF-кB signaling in prostate cancer: a promising therapeutic target? World J Urol 30(3): 303-310.

9. Staal J, Beyaert R (2018) Inflammation and NF- $\mathrm{kB}$ Signaling in Prostate Cancer: Mechanisms and Clinical Implications. Cells 7(9): 122.

10. Lawrence T (2009) The Nuclear Factor NF- $\kappa B$ Pathway in Inflammation. Cold Spring Harb Perspect Biol 1(6): a00165.

11. Ben-Neriah Y, and Karin M (2011) Inflammation meets cancer, with NF$\kappa \mathrm{B}$ as the matchmaker. Nat Immunol 12(8):715-23.

Your next submission with Juniper Publishers
will reach you the below assets
- Quality Editorial service
- Swift Peer Review
- Reprints availability
- E-prints Service
- Manuscript Podcast for convenient understanding
- Global attainment for your research
- Manuscript accessibility in different formats
( Pdf, E-pub, Full Text, Audio)
- Unceasing customer service
Track the below URL for one-step submission
https://juniperpublishers.com/online-submission.php

